\title{
Embolization to Left Anterior Descending Artery during Left Internal Mammary Artery Graft Angiography and Successful Recovery with Coronary Stenting
}

\author{
Tae-Hoon Kim, Michael Azrin and Juyong Lee* \\ Division of Cardiovascular Medicine, University of Connecticut Health Center, USA
}

Submission: July 04, 2017; Published: July 26, 2017

*Corresponding author: Juyong Lee, Assistant Professor, Division of Cardiovascular Medicine, Calhoun Cardiovascular Center, University of Connecticut School of Medicine, 263 Farmington Avenue, Farmington, CT 06030, USA, Tel: +1-860-679-3343/1-860-679-2058; Fax: +1-860-6793346; Email: jlee@uchc.edu

Abstract

A 75-year-old woman who underwent coronary artery bypass surgery 11 years ago underwent coronary angiography as a preoperative evaluation before non-cardiac surgery. During left internal mammary graft angiography, the patient developed sudden chest pain and was diagnosed with an embolic occlusion of distal left anterior descending coronary artery. We used balloon angioplasty with stent insertion. Successful restoration was achieved without further myocardial injury.

Keywords: Left internal mammary artery angiography; Embolization

Abbreviations: CABG: Coronary Artery Bypasses Graft; LAD: Left Anterior Descending Artery; NYHA: New York Heart Association; ASVG: Aorto-Saphenous Vein Graft; PDA: Posterior Descending Artery; CFA: Common Femoral Artery; LIMA: Left Internal Mammary Artery; SCA: Subclavian Artery; TIMI: Thrombolysis in Myocardial Infarction

\section{Introduction}

Embolization during diagnostic cardiac catheterization does not occur frequently. However, it may occur without warning. Percutaneous mechanical aspiration should be considered in first line treatment. However, it is not always possible because embolization sometimes occurs in very distal vessels. Thus, it is important to individualize the interventional strategy for each case. We describe a case of iatrogenic embolization into the left internal mammary artery resulting in distal left anterior descending artery occlusion and method to overcome this situation.

\section{Case Report}

A 75-year-old woman with ischemic cardiomyopathy and chronic obstructive lung disease was admitted to our hospital with NYHA functional class III dyspnea. She was previously found to have multi-vessel coronary artery disease and underwent coronary artery bypass graft (CABG) including a left internal mammary artery to the left anterior descending (LAD) artery and a orto-saphenous vein graft (ASVG) to the posterior descending artery (PDA) 11 years prior to the presentation. She had long history of cigarette smoking and also suffered from hypertension and hyperlipidemia. She was being considered for non-cardiac surgery and the patient was referred for preoperative evaluation before the surgery. Since she had exertional shortness of breath before the non-cardiac surgery, cardiac catheterization was performed.

Ultrasound guided sheath insertion was performed in the right common femoral artery (CFA). Then, left coronary angiography with 5 French Judkin left catheter was performed. Right coronary and ASVG angiography with 5 French Judkin right catheters were performed. We then, changed catheter to an internal mammary catheter and engaged the left subclavian artery. Left subclavian artery angiography was performed (Figure 1A). Then 0.035 j-tip wire was advanced to the distal left subclavian artery and the 
catheter was advanced over the wire (Figure 1B). After achieving successful catheter engagement of the LIMA, the contrastinjection was performed (Figure 1C). The patient complained of sudden chest pain. The angiography with full magnification of the LIMA to the distal LAD demonstrated an abrupt cut off at the distal LAD (Figure 1D). While administration of $100 \mathrm{IU} / \mathrm{kg}$ of heparin intravenously, the guiding catheter was exchanged to the 6 French VB-1 catheter (Cordis Corp., Miami, FL, USA). A 0.014 BMW guide wire was passed through the occluded artery (Figure 2A); the aspiration thrombectomy was performed with Pronto catheter (Vascular Solutions, Minneapolis, MN, USA) without successful blood flow restoration. Thus, balloon angioplasty using a $2.0 \mathrm{~mm}$ by $15 \mathrm{~mm}$ of balloon was achieved promptly (Figure $2 \mathrm{~B}$ ) and TIMI 3 flow was restored. There was residual stenos is with dissection at the balloon angioplasty site (Figure 2C). So, we finally treated that lesion with $2.5 \mathrm{~mm}$ by $15 \mathrm{~mm}$ bare metal stent (Figure 2D). The patient's angina was immediately improved.

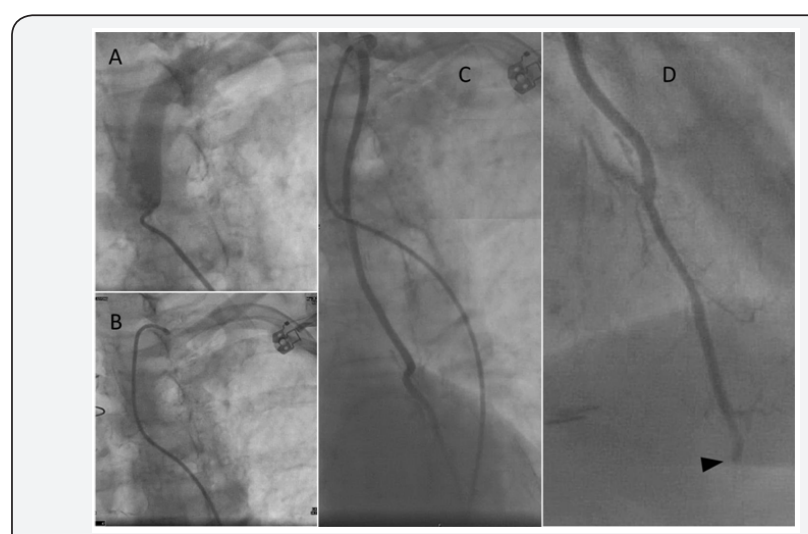

Figure 1: Subclavian angiography during diagnostic catheterization procedure. Figure 1A: A 4 French IMA catheter was placed in the proximal part of left subclavian artery. Figure 1B: A catheter was advanced and placed around the ostium of internal mammary artery. Figure 1C: LIMAAngiography revealed patent left internal mammary artery. Figure 1D: An abrupt cut off in distal LAD angiography (arrow head).

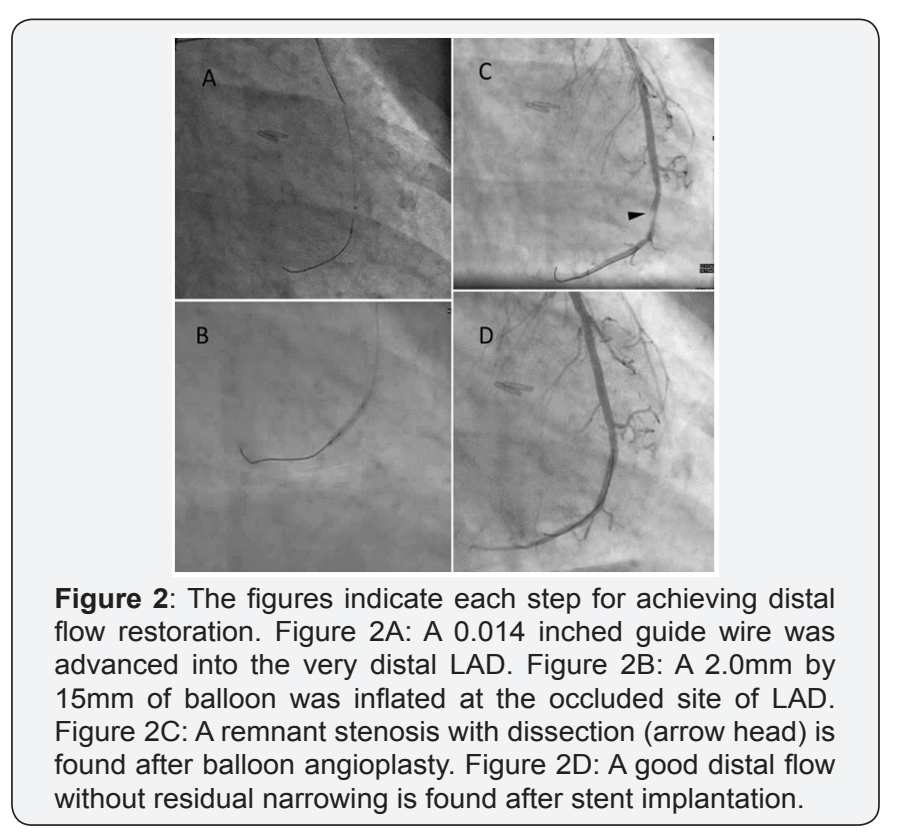

\section{Discussion}

Predictors of embolic complications include use of large diameters catheter or inappropriate use of anti-coagulation preparation [1]. However improved devices and skills, embolization during diagnostic catheterization is infrequent [2]. Nevertheless, the risk of unexpected coronary embolization occurs. It is therefore important to be aware of approaches for treating this condition.

One approach is mechanical aspiration [3-5]. This approach can restore blood flow if the embolus is a thrombus. Additionally, a variety of commercially available devices have been introduced. However these techniques or devices are not always approachable especially when the embolic debris is located in small caliber vessel or very distally. Use of a distal protection device before balloon angioplasty might seem like an appropriate risk intervention [6]. However this approach may not be indicated for simple diagnostic catheterization. Balloon dilatation with stent implantation may be the simplest method for small distal branch restoration and this method is usually necessary in case of athero-embolization to restore normal blood flow. However, stenting method might be a limited option in case a small caliber vessel.

Preventive strategies for embolization would be necessary for cardiac catheterization. Technically, gentle catheter manipulation would be necessary for reducing the rate of catheter tip injury. Careful catheter flushing and maintaining normal pressure wave form are also important. In another manner, pre-administration of intra-arterial or intra-venous heparin would be adequate for LIMA catheterization. However more importantly, aware of unpredictability of embolization and knowing various techniques for overcoming situation would be helpful for prompt management.

\section{References}

1. Paganin AC, Beghetto MG, Hirakata VN, Hilário TS, Matte R, et al. (2017) A Vascular Complications Risk (VASCOR) score for patients undergoing invasive cardiac procedures in the catheterization laboratory setting: A prospective cohort study. Eur J Cardiovasc Nurs 16(5): 409-417.

2. Eggebrecht $\mathrm{H}$, Oldenburg $\mathrm{O}$, Dirsch $\mathrm{O}$, Haude $\mathrm{M}$, Baumgart $\mathrm{D}$, et al. (2000) Potential embolization by atherosclerotic debris dislodged from aortic wall during cardiac catheterization: histological and clinical findings in 7,621 patients. Catheter Cardiovasc Interv 49(4): 389-394.

3. Dahm JB, Topaz O, Woenckhaus C, Staudt A, Möx B, et al. (2002) Laserfacilitated thrombectomy: a new therapeutic option for treatment of thrombus-laden coronary lesions. Catheter Cardiovasc Interv 56(3): 365-372.

4. Kahn JK, Hartzler GO (1990) Thrombus aspiration in acute myocardial infarction. Cathet Cardiovasc Diagn 20(1): 54-57.

5. Garcia-Tejada J, Jurado-Roman A, Hernandez F, Roberto MA, Javier MMN, et al. (2013) Guiding-catheter thrombectomy combined with distal protection during primary percutaneous coronary intervention of a saphenous vein graft. Cardiovasc Revasc Med 14(6): 356-358.

6. Kereiakes DJ, Turco MA, Breall J, Farhat NZ, Feldman RL, et al. (2008) A novel filter-based distal embolic protection device for percutaneous intervention of saphenous vein graft lesions: results of the AMEthyst randomized controlled trial. JACC Cardiovasc Interv 1(3): 248-257. 
This work is licensed under Creative Commons Attribution 4.0 License

DOI: $10.19080 /$ JOCCT.2017.06.555692

\section{Your next submission with Juniper Publishers} will reach you the below assets

- Quality Editorial service

- Swift Peer Review

- Reprints availability

- E-prints Service

- Manuscript Podcast for convenient understanding

- Global attainment for your research

- Manuscript accessibility in different formats ( Pdf, E-pub, Full Text, Audio)

- Unceasing customer service

Track the below URL for one-step submission https://juniperpublishers.com/online-submission.php 